\title{
Pelatihan Penghitungan Harga Pokok Produk dengan Metode Job Order Costing pada WF Printing
}

\author{
Fadrul $^{* a}$, Mimelientesa Irman $^{b}$, Sarli Rahmanc, Astri Ayu Purwatid \\ Institut Bisnis dan Teknologi Pelita Indonesia a, b, c, d \\ fadrul@lecturer.pelitaindonesia.ac.id
}

\begin{abstract}
Abstrak
Artikel ini membahas tentang kegiatan pelatihan penghitungan harga pokok produk (HPP) dengan metode job order costing pada WF Printing. Pelatihan ini dilakukan kepada karyawan WF Printing dengan sampel yang digunakan yaitu faktur berukuran $1 / 4$ folio dan $1 / 3$ folio. Hasil dari pelatihan ini menunjukkan bahwa dalam menjalankan usahanya WF Printing belum melakukan penghitungan HPP secara tepat, sehingga berdampak terhadap harga jual dan profit yang didapatkan. Diharapkan, dengan adanya pelatihan ini pemilik usaha dapat menerapkan dan melakukan penghitungan HPP secara tepat.
\end{abstract}

Keywords: HPP, job order costing, profit

\section{Pendahuluan}

Suatu perusahaan yang didirikan tentu mempunyai tujuan yang ingin dicapai. Salah satu wujud agar perusahaan efektif dan efesien dengan menerapkan sistem biaya yang handal sehingga bisa mendapatkan laba yang semaksimal mungkin dengan pemakaian biaya seminimal mungkin. Perusahaan harus bisa menetapkan biaya - biaya yang harus dikeluarkan sehingga biaya yang dikeluarkan dalam proses produksi akan menunjukkan besarnya harga pokok produksi itu sendiri. Harga pokok produksi itu sendiri merupakan komponen penting untuk menilai tingkat keberhasilan suatu perusahaan, laba (untung) atau rugi. Harga pokok produksi ini dapat membantu pemilik untuk mengambil keputusan mengenai suatu produk yang dihasilkan baik tentang harga jual maupun keputusan lainnya.

Harga pokok produksi adalah sejumlah biaya yang dikeluarkan dan digunakan untuk mengubah bahan baku menjadi bahan jadi (Mulyadi, 2012). Harga pokok produksi dalam suatu usaha merupakan bagian terbesar dari biaya yang dikeluarkan oleh pemilik usaha tersebut. Pemilik usaha harus cermat dan rinci dalam menghitung biaya - biaya yang dikeluarkan agar tidak terjadi penyimpangan - penyimpangan serta pemborosan biaya dalam proses produksi.

Penentuan harga pokok produksi dapat dilakukan melalui perhitungan berdasarkan pesanan dan proses. Perhitungan biaya berdasarkan pesanan diakumulasikan untuk setiap pesanan pelanggan (Siregar, 2013). Perhitungan biaya berdasarkan proses diakumulasikan berdasarkan departemen atau proses produksi (Salman, 2013). Untuk usaha percetakan lebih cenderung menggunakan perhitungan biaya berdasarkan pesanan.

Agar perhitungan biaya berdasarkan pesanan menjadi efektif, pesanan harus dapat diidentifikasikan secara terpisah. Agar rincian dari perhitungan biaya berdasarkan pesanan sesuai dengan usaha yang diperlukan, harus terdapat perbedaan penting dalam biaya per unit suatu pesanan dengan pesanan lain. Rincian mengenai suatu pesanan dicatat dalam kartu biaya pesanan yang dapat berbentuk kertas atau elektronik. Setiap kartu biaya pesanan mengumpulkan rincian untuk satu pesanan tertentu saja. Isi dan pengaturan dari kartu biaya 
pesanan berbeda dari satu bisnis dan bisnis lain. Perhitungan biaya berdasarkan pesanan mengakumulasikan biaya bahan baku langsung, tenaga kerja langsung, dan overhead yang dibebankan disetiap pesanan. Sering kali perusahaan industri yang berskala kecil kurang akurat dalam menentukan harga pokok produksi sehingga akan mengakibatkan harga jual yang terlalu rendah atau terlalu tinggi dan berdampak pada keuntungan yang diharapkan perusahaan.

Beberapa permasalahan yang terjadi dalam usaha percetakan yang ada di Pekanbaru yaitu perusahaan belum menghitung secara rinci biaya overhead pabrik yang dikeluarkan selama produksi dan tidak menghitung penyusutan dan pemeliharaan mesin yang digunakan. Penetapan harga pokok produksi belum mencerminkan seluruh biaya yang dikeluarkan untuk menghasilkan produk. Hal inilah yang mendasari dilakukannya pelatihan perhitungan harga pokok pada WF Printing, dimana selama ini perusahaan tidak melakukan klasifikasi biaya secara menyeluruh, sehingga berdampak pada kesalahan perhitungan harga pokok.

\section{Metode}

\section{Tempat dan Waktu Pelatihan}

Pelatihan ini bertempat di WF Printing yang beralamat di jalan Srikandi Kota Pekanbaru yang diikuti sebanyak 10 orang karyawan sedangkan waktu pelatihan diadakan pada hari Selasa tanggal 17 September 2019.

\section{Sampel}

Sampel yang digunakan dalam penelitian ini yaitu produksi faktur ukuran $1 / 4$ Folio (50 Blok) dan ukuran 1/3 Folio (30 Blok) yang diproduksi pada bulan Januari 2019.

\section{Metode Pelatihan}

Metode yang digunakan dalam pelatihan ini yaitu masing-masing peserta melakukan pengelompokan biaya-biaya dan melakukan perhitungan harga pokok produk dengan menggunakan perhitungan harga pokok produk pesanan (Job Order Costing). Menurut Blocher, et al. (2007), sistem biaya pesanan dilakukan dengan mengikuti alur berikut ini:

a. Biaya bahan baku

Job order costing menggunakan formulir permintaan bahan baku untuk mendokumentasikan dan mengendalikan bahan yang digunakan. Formulir permintaan bahan merupakan dokumen sumber yang digunakan oleh supervisor departemen produksi. Formulir permintaan bahan menunjukkan departemen, pesanan, dan proyek yang dibebani oleh bahan yang digunakan.

b. Biaya tenaga kerja langsung

Biaya tenaga kerja langsung dicatat dalam kartu biaya pesanan dengan menggunakan kartu waktu (time ticket) yang disiapkan setiap hari untuk setiap karyawan. Kartu waktu menunjukkan waktu karyawan yang digunakan untuk setiap pesanan, tarif gaji, dan biaya total yang dibebankan pada setiap pesanan.

c. Biaya overhead pabrik

Pembebanan atau alokasi overhead merupakan proses membebankan biaya overhead untuk pesanan yang sesuai. Alokasi diperlukan karena biaya overhead tidak dapat ditelusuri kepesanan individual. Ada tiga pendekatan dalam membebankan biaya overhead pabrik keberbagai pesanan tentang tiga pendekatan yaitu: 
$\checkmark$ Actual costing adalah pendekatan dalam pembebanan biaya secara nyata yang benar-benar terjadi dalam proses pembuatan pesanan, dalam pendekatan pembebanan biaya overhead pabrik suatu pesanan dengan menggunakan actual costing akan lebih sulit dalam menghitung pembebanan biaya overhead.

$\checkmark$ Normal costing adalah pendekatan pembebanan biaya overhead pabrik dengan menggunakan dasar alokasi ini merupakan hasil perhitungan data yang telah dikelola pada tahun sebelumnya.

$\checkmark$ Standar costing merupakan biaya yang ditetapkan lebih dahulu menurut aturan secara efisiensi yang berlaku bagi suatu perusahaan tertentu yang diperlukan untuk menghasilkan suatu produk atau barang.

\section{Hasil dan Pembahasan}

\section{Biaya Bahan Baku}

Bahan baku yang digunakan adalah kertas. Biaya bahan baku dihitung dengan cara menghitung seluruh biaya bahan baku yang digunakan dalam pencetakan faktur. Sehingga didapat biaya per blok faktur. Besarnya bahan baku yang dikeluarkan WF Printing untuk lebih jelas dapat dilihat pada tabel berikut :

Tabel 1. Perhitungan Biaya Bahan Baku Faktur uk. 1/4 Folio

\begin{tabular}{lcrlr}
\hline \multicolumn{1}{c}{ Bahan Baku } & $\begin{array}{c}\text { Total } \\
\text { Pemakaian }\end{array}$ & \multicolumn{2}{c}{$\begin{array}{c}\text { Harga } \\
\text { Satuan }\end{array}$} & \multicolumn{2}{c}{ Total } \\
\hline Kertas Putih (Top) & $208 \mathrm{lbr}$ & Rp. 82 & Rp. & 17.056 \\
Kertas Pink (Middle) & $208 \mathrm{lbr}$ & Rp. 84 & Rp. & 17.472 \\
Kertas Kuning (Bottom) & $208 \mathrm{lbr}$ & Rp. 78 & Rp. & 16.224 \\
Alas Tulis & $15 \mathrm{lbr}$ & Rp. 200 & Rp. & 3.000 \\
Sampul & $15 \mathrm{lbr}$ & Rp. 1.500 & Rp. & 22.500 \\
Tinta & - & Rp. 3.000 & Rp. & 3.000 \\
\hline JUMLAH & & & Rp. & 79.252 \\
\hline
\end{tabular}

Tabel 2. Perhitungan Biaya Bahan Baku faktur uk. 1/3 Folio

\begin{tabular}{lcrlr}
\hline \multicolumn{1}{c}{ Bahan Baku } & $\begin{array}{c}\text { Total } \\
\text { Pemakaian }\end{array}$ & \multicolumn{2}{c}{$\begin{array}{c}\text { Harga } \\
\text { Satuan }\end{array}$} & \multicolumn{2}{c}{ Total } \\
\hline Kertas Putih (Top) & $167 \mathrm{lbr}$ & Rp. 82 & Rp. & 13.694 \\
Kertas Pink (Middle) & $167 \mathrm{lbr}$ & Rp. 84 & Rp. & 14.028 \\
Kertas Kuning (Bottom) & $167 \mathrm{lbr}$ & Rp. 78 & Rp. & 13.026 \\
Alas Tulis & $10 \mathrm{lbr}$ & Rp. 200 & Rp. & 2.000 \\
Sampul & $10 \mathrm{lbr}$ & Rp. 1.500 & Rp. & 15.000 \\
Tinta & - & Rp. 3.000 & Rp. & 3.000 \\
\hline JUMLAH & & & Rp. & 60.748 \\
\hline
\end{tabular}

\section{Biaya Tenaga Kerja Langsung}

Biaya tenaga kerja langsung di hitung berdasarkan biaya yang sesungguhnya terjadi, yang digunakan untuk menghasilkan produk. Pada WF Printing sistem penggajian dilakukan berdasarkan upah harian pengerjaan pesanan. 


\begin{tabular}{|c|c|c|c|c|}
\hline Keterangan & $\begin{array}{c}\text { Jumlah } \\
\text { Karyawan }\end{array}$ & $\begin{array}{c}\text { Hari } \\
\text { Pengerjaan }\end{array}$ & $\begin{array}{l}\text { Upah } \\
\text { perhari }\end{array}$ & $\begin{array}{c}\text { Jumlah } \\
\text { Harga } \\
\end{array}$ \\
\hline Uk. $1 / 4$ Folio & 1 & 2 Hari & 65.000 & Rp. 130.000 \\
\hline Uk. 1/3 Folio & 1 & 2 Hari & 65.000 & Rp. 130.000 \\
\hline
\end{tabular}

\section{Biaya Overhead Pabrik}

Biaya overhead pabrik (BOP) dapat digolongkan menjadi biaya overhead pabrik tetap dan variabel.

1. Biaya Overhead Pabrik Tetap

Biaya overhead pabrik tetap pada WF Printing adalah :

a. Beban sewa rumah

Merupakan beban yang dikeluarkan secara rutin setiap bulannya. Karena WF Printing memiliki rumah sendiri untuk menjalankan usahanya sehingga perusahaan tidak mengeluarkan biaya sewa.

b. Biaya penyusutan mesin, bangunan dan kendaraan

Penyusutan adalah alokasi jumlah suatu aktiva yang dimasukkan sepanjang masa manfaat yang diestimasi. Penggunaan mesin dan peralatan menyebabkan penyusutan nilai dari mesin dan peralatan sehingga berkurangnya nilai guna mesin dan peralatan. Untuk menghitung penyusutan mesin dan peralatan yang dipakai percetakan WF Printing dapat dilihat sebagai berikut :

Tabel 4. Perhitungan Penyusutan Mesin dan Peralatan

\begin{tabular}{|c|c|c|c|c|c|c|c|}
\hline No & Keterangan & Unit & $\begin{array}{c}\text { Tahun } \\
\text { Perolehan }\end{array}$ & $\begin{array}{c}\text { Harga per } \\
\text { unit (Rp) }\end{array}$ & Total (Rp) & $\begin{array}{l}\text { Masa } \\
\text { Pakai }\end{array}$ & $\begin{array}{l}\text { Penyusutan } \\
\text { per tahun } \\
\text { (Rp) }\end{array}$ \\
\hline 1 & Mesin GTO & 1 & 2010 & 140.000 .000 & 140.000 .000 & $15 \mathrm{Th}$ & 9.333.333 \\
\hline 2 & Mesin Potong & 1 & 2012 & 10.500 .000 & 10.500 .000 & $10 \mathrm{Th}$ & 1.050 .000 \\
\hline 3 & Mesin Besti & 2 & 2010 & 40.000 .000 & 80.000 .000 & $15 \mathrm{Th}$ & 5.333 .333 \\
\hline 4 & $\begin{array}{l}\text { Mesin } \\
\text { Printplate } \\
\text { Kertas }\end{array}$ & 1 & 2012 & 2.850 .000 & 2.850 .000 & $10 \mathrm{Th}$ & 285.000 \\
\hline 5 & Gedung & 1 & 2005 & 50.000 .000 & 50.000 .000 & $20 \mathrm{Th}$ & 2.500 .000 \\
\hline 6 & Kendaraan & 1 & 2013 & 65.000 .000 & 65.000 .000 & $10 \mathrm{Th}$ & 6.500 .000 \\
\hline 7 & Lampu & 4 & 2019 & 60.000 & 240.000 & $1 \mathrm{Th}$ & 240.000 \\
\hline 8 & Printer & 1 & 2016 & 3.500 .000 & 3.500 .000 & $3 \mathrm{Th}$ & 1.166 .666 \\
\hline 9 & Komputer & 1 & 2015 & 2.500 .000 & 2.500 .000 & $5 \mathrm{Th}$ & 500.000 \\
\hline 10 & Scanner & 1 & 2016 & 1.500 .000 & 1.500 .000 & $3 \mathrm{Th}$ & 500.000 \\
\hline \multicolumn{2}{|c|}{ Jumlah per tahun } & & & & & & 27.408 .332 \\
\hline \multicolumn{2}{|c|}{ Jumlah per bulan } & & & & & & 2.284 .028 \\
\hline \multicolumn{2}{|c|}{ Jumlah per hari } & & & & & & 76.134 \\
\hline
\end{tabular}

Sumber : Data diolah (2019)

c. Biaya Perawatan Mesin

Biaya perawatan mesin dikeluarkan untuk memelihara mesin dan perawatan agar lebih tahan lama dalam masa pemakaiannya 
Tabel 5. Biaya Perawatan Mesin

\begin{tabular}{|c|c|c|c|c|}
\hline No & Keterangan & $\begin{array}{c}\text { Jumlah } \\
\text { Unit }\end{array}$ & Harga & Junlah Harga \\
\hline 1 & Oli & 1 & Rp. 35.000 & Rp. 35.000 \\
\hline 2 & Semprotan & 1 & Rp. 15.000 & Rp. 15.000 \\
\hline 3 & Spons & 1 & Rp. $\quad 5.000$ & Rp. $\quad 5.000$ \\
\hline 4 & Ultra clean & 1 & Rp. 25.000 & Rp. 25.000 \\
\hline 5 & Plate cleaner & 1 & Rp. 75.000 & Rp. 75.000 \\
\hline 6 & Fountek Plus & 1 & Rp. 20.000 & Rp. 20.000 \\
\hline \multicolumn{2}{|c|}{ Jumlah per 3 bulan } & & & Rp. 175.000 \\
\hline \multicolumn{2}{|c|}{ Jumlah per hari (90 hari) } & & & Rp. 2.000 \\
\hline
\end{tabular}

2. Biaya Overhead Pabrik Variabel

Biaya overhead pabrik variabel pada WF Printing adalah sebagai berikut :

a. Biaya Listrik

Biaya listrik adalah biaya yang digunakan selama proses percetakan faktur. Setiap mesin yang digunakan dalam proses pencetakan menggunakan tenaga listrik. Biaya listrik termasuk kedalam biaya semi variabel karena biaya ini dikeluarkan rutin setiap bulan tetapi dengan nilai yang tidak menentu tergantung penggunaannya. Pada WF Printing untuk mengerjakan pesanan 50 blok uk. 1/4 folio dan 30 blok uk. 1/3 folio menggunakan waktu kurang lebih 2 hari, untuk lebih jelas dapat dilihat pada tabel berikut :

Tabel 6. Penggunaan Listrik dan Telepon

\begin{tabular}{cccc}
\hline Pemakaian /Bulan & Biaya/Hari & $\begin{array}{c}\text { Waktu } \\
\text { Penyelesaian } \\
\text { Pesanan }\end{array}$ & Total Biaya \\
\hline Rp. 1.000 .000 & Rp. 33.300 & 2 & Rp. 66.600 \\
\hline & Jumlah & Rp. 66.600 \\
\hline & Sumber : Data diolah (2019)
\end{tabular}

b. Minyak Tinner

Tinner digunakan sebagai bahan pembersih noda tinta.

Tabel 7. Penggunaan Minyak Tinner

\begin{tabular}{llcl}
\hline Keterangan & Pemakaian & $\begin{array}{c}\text { Harga/ } \\
\text { Liter }\end{array}$ & Jumlah \\
\hline Minyak Tinner & 1/4 liter & Rp. 6.250 & Rp. 1.563 \\
\hline \multicolumn{3}{c}{ Jumlah } & Rp. 1.563 \\
\hline & Sumber : Data diolah (2019) &
\end{tabular}


c. Bahan Penolong

Bahan penolong adalah bahan - bahan yang digunakan dalam proses produksi yang dikenakan langsung terhadap bahan baku yang sifatnya membantu atau mendukung untuk kelancaran proses produksi. Bahan penolong memiliki biaya yang relatif kecil. Pada percetakan WF Printing terdapat beberapa jenis bahan penolong. Untuk lebih jelas dapat dilihat pada tabel berikut :

Tabel 8. Biaya Bahan Penolong

\begin{tabular}{|c|c|}
\hline Keterangan & Biaya Bahan Penolong \\
\hline Lem Q Bond & Rp. 100.000 \\
\hline Kuas & Rp. $\quad 15.000$ \\
\hline Spidol & 5.000 \\
\hline Cutter & Rp. 12.000 \\
\hline Rol & 5.000 \\
\hline Waterpass & Rp. $\quad 17.000$ \\
\hline Wadah & Rp. 15.000 \\
\hline Kertas Film & 5.500 \\
\hline Jumlah per 3 bulan & Rp. 174.500 \\
\hline Jumlah per hari (90 hari) & 1.900 \\
\hline
\end{tabular}

maka perhitungan untuk biaya overhead pabrik dalam proses pencetakan faktur pada WF Printing dapat dilihat pada tabel berikut :

Tabel 9. Perhitungan Biaya Overhead Pabrik

\begin{tabular}{lcc}
\hline \multicolumn{2}{c}{ Keterangan } & Jumlah \\
\hline BOP Tetap : & & \\
Penyusutan Mesin dan Kendaraan & Rp. & 76.134 \\
Perawatan Mesin & Rp. & 2.000 \\
BOP Variabel : & & \\
Biaya Listrik & Rp. & 60.600 \\
Biaya Bensin & Rp. & 15.000 \\
Biaya Tinner & Rp. & 1.563 \\
Biaya Bahan Penolong & Rp. & 1.900 \\
\hline \multicolumn{2}{c}{ Jumlah } & Rp. \\
\hline \multicolumn{2}{c}{ Sumber : Data diolah (2019) }
\end{tabular}

Perhitungan Harga Pokok Produksi dengan Metode Job Order Costing

Berdasarkan rincian biaya produksi yang telah di perhitungkan, maka perhitungan harga pokok produksi dengan metode Job Order Costing dapat dilihat pada tabel : 
Tabel 10. Perhitungan HPP Metode Job Order Costing Faktur uk. 1/4 folio

\begin{tabular}{llc}
\hline \multicolumn{1}{c}{ Keterangan } & \multicolumn{2}{c}{ Biaya } \\
\hline Bahan Baku Langsung & Rp. & 79.252 \\
Tenaga Kerja Langsung & Rp. & 130.000 \\
Biaya Overhead Pabrik & Rp. & 163.197 \\
\hline Harga Pokok Produk & Rp. & 372.449 \\
\hline Harga Per Blok & Rp. & 7.500 \\
\hline
\end{tabular}

Berdasarkan perhitungan dapat dilihat bahwa harga pokok produk Faktur ukuran . $1 / 4$ folio sebanyak 50 blok adalah sebesar Rp. 7.500,--

Tabel 11. Perhitungan HPP Metode Job Order Costing Faktur uk. ${ }^{1 / 3}$ folio

\begin{tabular}{llr}
\hline \multicolumn{2}{c}{ Keterangan } & \multicolumn{2}{c}{ Biaya } \\
\hline Bahan Baku Langsung & Rp. & 60.748 \\
Tenaga Kerja Langsung & Rp. & 130.000 \\
Biaya Overhead Pabrik & Rp. & 163.197 \\
\hline Harga Pokok Produk & Rp. & 353.945 \\
\hline Harga Per Blok $\quad$ Rp. & 11.800 \\
\hline
\end{tabular}

Berdasarkan perhitungan dapat dilihat bahwa harga pokok produk Faktur ukuran 1/3 folio sebanyak 50 blok adalah sebesar Rp. 11.800,-.

\section{Simpulan}

Dari hasil perhitungan saat pelatihan, maka dapat disimpulkan bahwa (1) Perhitungan harga pokok dengan metode Job Order Costing dilakukan disaat pesanan datang, sehingga harga pokok produk dipengaruhi oleh banyak sedikitnya pesanan. (2) Perhitungan harga pokok dengan metode Job Order Costing lebih akurat dan mencerminkan biaya-biaya yang terjadi, sehingga penetapan harga pokok lebih akurat.

Adapun saran dari hasil pelaksanaan pelatihan ini, antara lain (1) Diharapkan pihak percetakan dapat menghitung biaya-biaya yang dikeluarkan dalam produksi lebih teliti. (2) Dengan adanya pelatihan ini, pihak percetakan diharapkan menghitung harga pokok produksi dengan menggunakan metode Job Order Costing.

\section{Daftar Pustaka}

Blocher, Edward J., Chen, Kung, Cokins, Gary., Lin, Thomas W. 2007. Manajemen Biaya, Edisi 3. Salemba Empat. Jakarta

Mulyadi. 2012. Akuntansi Biaya. Penerbit STIM-YKPN. Yogyakarta.

Salman, Kautsar Riza. 2013. Akuntansi Biaya : Pendekatan Product Costing. Akademi Permata. Jakarta.

Siregar, Baldric. 2013. Akuntansi Biaya, Edisi Kedua. Salemba Empat. Jakarta. 